\title{
Teachers' SMK And PCK OF Mathematics And Science Affect Teaching In Gaborone Preschools
}

\author{
Prof. Kabita Bose (PhD) \\ Department of Primary Education, \\ Faculty of Education, \\ University of Botswana, Gaborone, Botswana \\ Ms. Grace Seetso \\ Department of Primary Education, \\ Faculty of Education, University of Botswana, \\ Gaborone, Botswana
}

\begin{abstract}
The current study presents an account of mathematics and science knowledgebase of private Gaborone preschool teachers and assesses its influence on their classroom teaching. It assesses their Subject Matter Knowledge (SMK) and Pedagogical Content Knowledge (PCK) and scales their views on the Best Practices for mathematics and science teaching in preschools. A pragmatic paradigm with a concurrent mixed-method mode was used to conduct this study. Using a random-purposive sampling procedure, 64 preschool teachers were selected. Questionnaire and focus group discussions were used for data collection. The quantitative data was analysed using descriptive analysis and presented with the help of frequency Tables and Graphs. The qualitative data was coded and synthesised to receive meaningful information. The findings show that $80 \%$ of teachers were trained as primary school teachers; only $14 \%$ had professional training in Early Childhood Education (ECE). It further revealed that the teachers had SMK; however, were less proficient in PCK which affected their classroom practices, despite having ample material resources. The preschool teachers viewed the establishment of the Science Center/s for young children and strong administrative support as best practices for teaching mathematics and science in preschools.
\end{abstract}

Keywords: ECE, early childhood education, mathematics, science, knowledgebase, PCK, SMK.

\section{INTRODUCTION}

Students in Botswana don't have interest in mathematics and science and they perform poorly at all levels (Mathangwane, 2011). It is often noticed that students here often abstain from taking mathematics and science subjects at tertiary levels. Mathematics and science play a crucial role in our lives. The education stakeholders, therefore, should persevere to make mathematics and science attractive; set stage to be accountable for providing quality teachinglearning process at all levels.

This research project (No.: R955 ECC\&E) was conducted (2012-2015) to seek a deeper understanding of teaching/learning process of mathematics and science. Preschool being the foundation level became an important and integral part of this project. Private institutions being predominantly available during the said period were chosen as target population of this project. It revealed that there is a gap in classroom practices which needs to be bridged to improve such a scenario (Bose, 2012; Bose \& Seetso, 2016). The project further researched the knowledgebase, the Subject Matter Knowledge (SMK) and Pedagogical Content Knowledge 
(PCK) of Gaborone private preschool teachers as that can have an impact on their classroom practices. The study also assessed the preschool teachers' perspectives regarding Best Practices in mathematics and science teaching in preschools. The current paper presents the outcome of this part of the study (teachers' knowledgebase and Best Practices).

Firstly, the researchers present the contextual background of Botswana's Preschool Education Systems to acquaint the readers and enable them to follow it better. In Botswana, preschool education was initially offered by commercial enterprises, independent childcare providers, and community and faith based programmes, with their own curriculum and staffing policy till recently. In 2015, the government of Botswana rolled out a two-year preschool program and introduced Reception Classes to public/government primary schools, for children aged between $4 \frac{1}{2}$ and $5 \frac{1}{2}$ years. Currently, it has covered $75 \%$ of public/government primary schools and the remaining 25\% would be done by 2020 (Republic of Botswana, 1994; Republic of Botswana, 2015). In 2015, a preschool curriculum was also introduced (Republic of Botswana, 2017); nonetheless there is still a scarcity of trained teachers in ECE in private preschools of Gaborone (as per Anecdotal Evidence).

\section{MATHEMATICS AND SCIENCE IN PRESCHOOLS}

Grasping of mathematics and science concepts is crucial, and efforts should be made to make them simple, attractive, motivating to arouse children's interest in them. Mathematics and Science in schools should be taught in an interesting manner so that the children take a liking in those subjects, study them, and live through the mathematical and scientific experiences enthusiastically. It would thus be most appropriate to create such an environment in the foundation level, i.e. in preschools, when students are still at an impressionable age, and gather experiences that form the core of the latter competence.

Children enter preschools with a range of concepts gathered from informal experiences, through active exploration of their environments; they learn and construct their own knowledge by doing and discovering (Essa, 2013). The preschool teachers thus need to build on the childrens' existing concepts, create a learning environment, and provide opportunities for development of important understanding of the concepts. Stimulating activities involving the process of inquiry/discovery are crucial to form concepts, develop logical thinking, classify information, reason opportunities, solve problems and make decisions; rather than memorizing of isolated mathematics and science concepts. The teachers need to cultivate childrens' curiosity and interest through classroom activities for learning difficult mathematics and science concepts. Acquisition of such concepts need to be made an integral part of the daily life activities, chosen carefully by teachers, with hands-on materials to believe and see it happen, as mathematics and science are not intuitive (Samuelsson \& Johansson, 2006; Moomaw, 2011; Gallenstein, 2004). The teachers need to plan, support, and guide children using varied teaching strategies in an environment that encourages learning through social relationships. They need to facilitate and extend children's learning within the holistic nature of the EC curriculum, without using traditional teacher centred method. They must become active participator with children who are active and inventive, to facilitate mastery of concepts in an interesting, easy and enjoyable manner.

Mathematics and science content for young children should be context specific; i.e., related to the physical learning environment, children, teachers, incidences and examples of real life and the context of play (Hedges \& Cullen, 2005a; Oers, 2010). Use of a context and content specific, developmentally appropriate curriculum which refers to a specific region, background of children and their families becomes essential (Kallery \& Psillos, 2001; Darling-Hammond, 2000; Garbett, 2003; Clements, 2001). Teachers must understand how preschool children 
learn and what they should learn, in addition to content knowledge and the knowledge of children's different experiences in different subject areas, to provide challenging situation and stimulation for developing mathematics and science skills and technological competence. The teachers should be flexible and reflect on their own choices of content whilst critically analysing and evaluating them. Through play, they should try and provide the most enriching environment for learning of concepts, and make the child take keen interest in them whilst absorbing and exploring the physical world and getting the essence of scientific and mathematical understanding. Play indeed can be used as an unconscious preparation for future education in mathematics and Natural Sciences.

\section{THEORETICAL/CONCEPTUAL FRAMEWORK}

The above argument therefore emphasises the preschool teachers' possession of a sound knowledge base and ability to combine the child's understanding and skills, character and performance and devices and values. In general, the knowledge base refers to the Subject Matter Knowledge (SMK), pedagogy, and the instructional strategies used for teaching in the classrooms. The SMK provides the knowledge of the content of a subject, the concepts embedded in it, principles, laws and models; syntactic content knowledge with agreements, norms, paradigms and ways of establishing new knowledge that are acceptable (LIU, 2010). SMK often influences what and how the teachers teach. The Pedagogical Content Knowledge (PCK) on the other hand, refers to the knowledge that is an amalgamation of content and pedagogy that is uniquely the teachers' special form of professional understanding (Fernandez, 2014). PCK refers to the contextual knowledge, the knowledge regarding the learning environment, childrens' experiences, and the daily activities, the pedagogical and didactical strategies that are adopted for teaching in the classroom. Shulman (1986) distinguished it as a knowledge of a teacher from the knowledge of a subject matter specialist, and defined as:

[...] which goes beyond knowledge of subject matter per se to the dimension of subject matter knowledge for teaching. I still speak of content knowledge here, but of the particular form of content knowledge that embodies the aspects of content most germane to its teachability. Within the category of pedagogical content knowledge I include, for the most regularly taught topics in one's subject area, the most useful forms of representation of those ideas, the most powerful analogies, illustrations, examples, explanations, and demonstrations-in a word, the ways of representing and formulating the subject that makes it comprehensible to others. Since there are no single most powerful forms of representation, the teacher must have at hand a veritable armamentarium of alternative forms of representation, some of which derive from research whereas others originate in the wisdom of practice. p. 9 


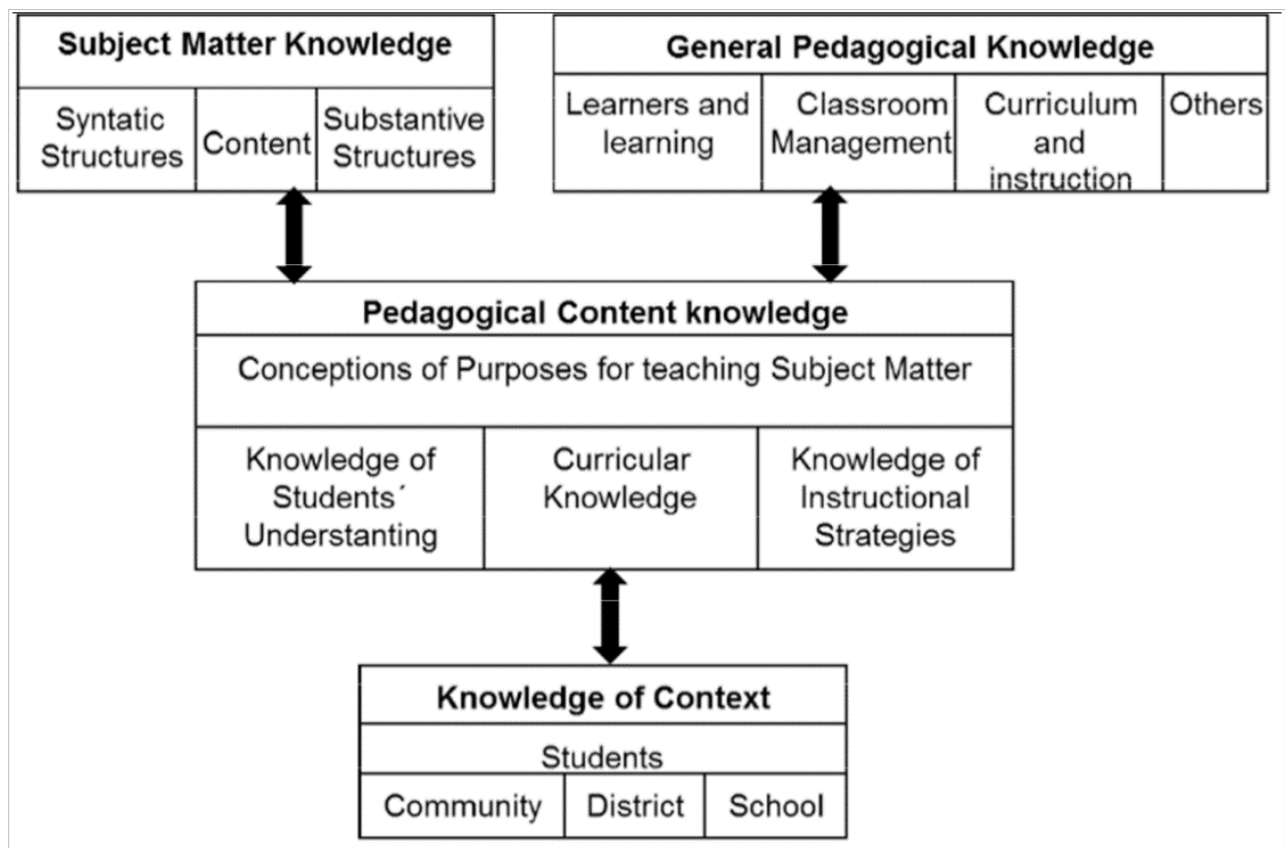

Figure 1. Grossman's Model of Teacher Knowledge (19901).

The model of teachers' knowledge base (Grossman, 1990) as given in Figure 1 above emphasises PCK as the core of teacher knowledge base, interacting with SMK, General Pedagogical Knowledge and Knowledge of Context. In this model, PCK is seen as the transformation of pedagogical knowledge as context and content specific. The model includes purposes of teaching, knowledge of students' understanding, curricular knowledge and knowledge on instructional strategies as the central aspect, which influences and gets influenced by general pedagogical knowledge, SMK and contextual knowledge. It also represents hierarchy of the knowledge and the relationship between the other kinds of knowledge. General pedagogical knowledge, on the other hand refers to general knowledge and beliefs concerning learning and learners as well as knowledge of general principles of instruction. This model emphasises the relevance of teachers' knowledge of context, the districts, students' expectations, and the school "culture" useful for classroom practices (Figure 1). Teaching of mathematics and science to preschool children involves a whole lot of transformations of relevant SMK into a form that is comprehensible to students. PCK thus stands to be more relevant than SMK in teaching/learning process of preschoolers. It transforms instructional strategy from a high level, structured one, to a child's developmental level of understanding perhaps through play, songs/rhymes and stories.

\section{OBJECTIVES}

The current study thus is guided by the Grossman's Model of teacher knowledgebase and tries to find out how does that affect the classroom practices. It also tries to find out the teachers' perspectives of Best Practices that could fill the gap and provide a way forward to a novel instructional strategy. The objectives of the study were to find out the:

1. Preschool teachers' SMK of mathematics and science

2. Preschool teachers' PCK of mathematics and science

3. Effect of preschool teachers' knowledgebase on their classroom practices

4. Best Practices of Teaching of mathematics and science in preschools

\section{METHOD}

A set of methods and principles that are used to carry out research are termed as methodology (Wiersma \& Jurs , 2009). Paradigms are the inferred rules which guide researchers to operate when choosing approaches in a research (Creswell, 2013). Off late, mixed methods research 
have become very popular and pragmatism have been identified as the appropriate paradigm for conducting mixed methods research. Creswell (2013) describes this type of mixed methods research as both a method and methodology for conducting research that involves collecting, analyzing, and integrating quantitative and qualitative research in a single study or a longitudinal program of inquiry. Mixed method research helps in looking at multiple angles regarding the research problem, using qualitative research and then generalizing findings to a large population using quantitative research.

This study used a pragmatic paradigm with a concurrent-mixed-method mode using quantitative and qualitative approaches, to gain deeper understanding and corroboration, while balancing the weaknesses inherent to using a single approach (Castro, Kellison, Boyd, \& Kopak, 2010). This approach enabled the researcher to focus on what works as the truth concerning the research objectives under study; view mixed method approach as a link; adopt data collection strategies in a concurrent and chronological manner that are drawn from quantitative and qualitative sources; and provide flexibility in analysis; and enable employment of analysis of both quantitative and qualitative data (Tashakkori \& Teddlie, 2009; Creswell, 2013). The concurrent-mixed-method helped in using qualitative research and side by side quantify findings to a large population using quantitative data.

Population of the study was private preschool of Gaborone. Anecdotal records show that there are 1593 preschools in entire Botswana; 838 (53\%) private preschool and 755 (47\%) public primary schools which are being provided with preschools. Out of total number of private preschools in Botswana, 113 (13.5\%) are located in Gaborone (unpublished Local Government Archives). The justification for choosing private schools from Gaborone was thus due to the evidence of the highest concentration of preschool programs in the capital, which were well established for decades, and were actually operational.

To choose the sample, a random-purposive sampling technique was adopted. Private schools that catered to children of $3 \frac{1}{2}$ to 5 years of age were chosen purposively from Gaborone. For a descriptive design at least $20 \%$ of the population should be considered and a quantitative sampling requires a minimum of 30 participants (Gay, Mills, \& Airasian , 2009). So, the researcher selected 50 preschools $(50 \%)$ out of 113 private preschools at random, and 100 preschool teachers @ of 2 teachers from each one of them were selected for the study. Fifteen teachers were selected at random for Focus Group Interviews.

The instruments used were Questionnaire and Focus Group Discussions, which were adapted contextually. Out of 100 questionnaires distributed, only sixty-four (64) returned. The questionnaire consists of different sections, i) Section A: Demographic data, ii) Section B: Closed, Multiple Choice questions a, iii) Section C: Open-ended questions addressing issues regarding the SMK and PCK of preschool teachers, and the Best Practices. The demographic data was used for analysing the relationship between the qualification of participants and their knowledgebase.

In addition, Focus Group discussions were conducted for concurrent triangulation purposes to bridge the gap. The researcher trained Research Assistants (RA) through workshops to administer the questions and conduct Focus Group Interviews. The Council invited the preschool teachers to participate in a workshop followed by a focus group interview and only 12 preschool teachers participated in it. Appropriate measures were taken to seek approval from the competent authority certified by the institutions for conducting the research in preschools. 
Prior to data collection, the researchers obtained an approval from the Ministry of Basic Education (MoBE) (the then Ministry of Education and Skills Development) to conduct the study and collected an informed consent form duly signed from the participants, with an assurance of maintaining confidentiality and anonymity throughout the study. The Instruments were piloted and tested for its validity and reliability by using 4 preschools from the selected sample (these did not form the part of the study).

Statistical Package for Social Sciences (SPSS), version 23 and Microsoft Excel were used for quantitative, descriptive data analysis and results were presented in percentages with the help of frequency Tables and Graphs. For qualitative data analysis obtained from Open-ended questions of Questionnaire, and Focus Group Interviews, the researcher worked with the data, organised them, broke them into manageable units, coded and synthesised them, and derived some patterns, compare them to receive meaningful information (Bogdan \& Biklen, 2003). To analyse qualitative data, the participants' verbatim and statements were categorized (Braun \& Clarke, 2006). The researcher triangulated all the data (Creswell, 2013) in order to gain a broader understanding of the issues being investigated and reduced the risks of systematic biases.

\section{RESULTS}

The results present data regarding the classroom practices adopted, the SMK and PCK of the teachers, the didactical consideration the preschool teachers made, and the Best Practices that could be identified.

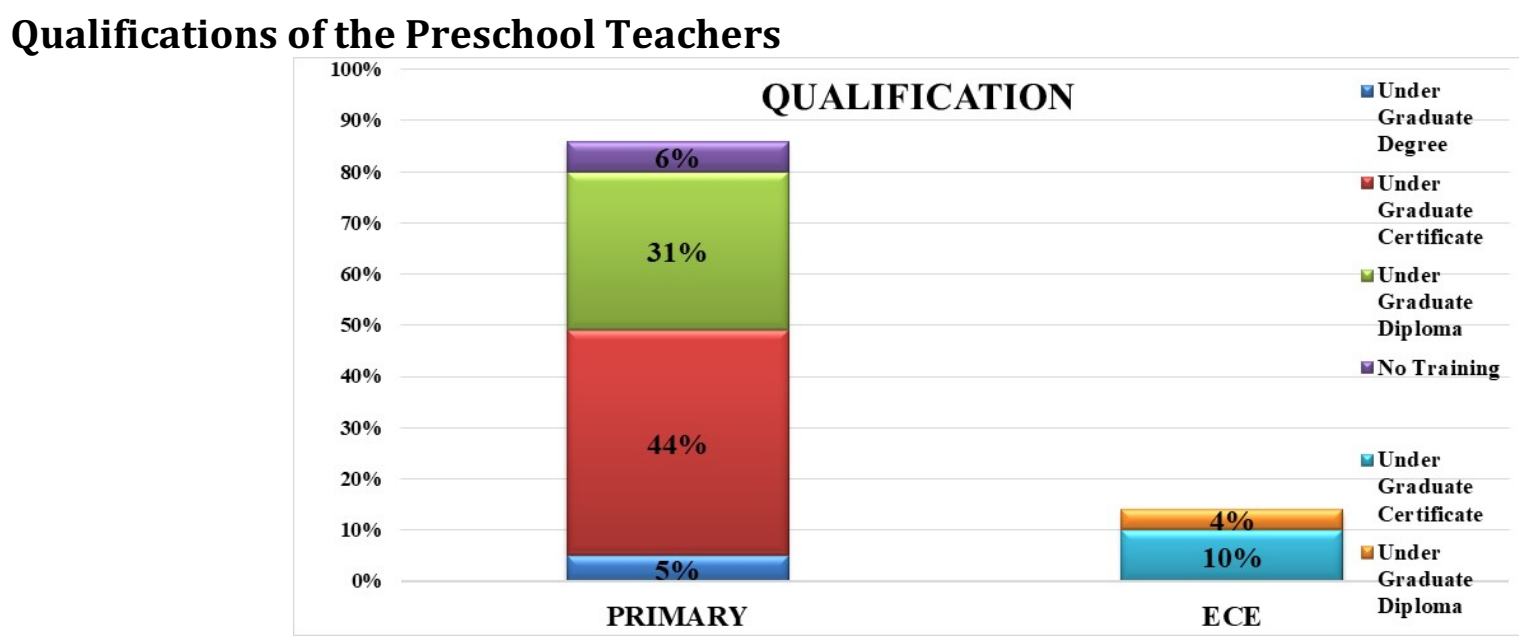

Figure 2. Professional Qualification of Preschool Teaches.

Since the study is investigating the SMK and PCK of preschool teachers' it was necessary for the researcher to present their qualification profile. Only $14 \%$ of the teachers received a formal training in ECE and possessed either a certificate or a diploma in ECE (10\% Certificate and 4\% Diploma), the remaining $75 \%$ of preschool teachers were trained as Primary Education Teachers at undergraduate level with mathematics, science or other subject areas (5\%-Degree; 31\%-Diploma, 44\%-Certificates); and 7\% (Standard 7, Junior Secondary or Form 5 pass outs) were without any training (see Figure 2).

\section{SMK and PCK of Pre-School Teachers}

Table 1 (see below) shows that 71\% preschool teachers had SMK of mathematics and science concepts, both the conventional and the contemporary ones. Their classroom practices revealed that nearly $2 / 3$ rds of them (64\%) used mathematical activities related to rote counting, copying numbers, and tracing patterns, additions and subtractions. Only 16\% 
however, did science activities, which never included any experiments, exploration, discovery, water play, weather lessons, fun activities, storytelling, games/songs/rhymes, figure plays, and nature walks. On probing further, the teachers said that:

- Science is more demanding

- Children develop basic mathematical concepts from daily life activities at home

- Mathematics is easy to teach and not a high order thinking subject like science

- Parents and society demand teaching of mathematics

Table 1

SMK of Teachers

\begin{tabular}{ll}
\hline Teachers' Knowledgebase & Yes \\
\hline & \\
Knowledge of Mathematics and Science Concepts & $71 \%$ \\
Engagement in Mathematics Activities & $64 \%$ \\
Engagement in Science Activities & $16 \%$ \\
Use of Materials Available & $33 \%$ \\
\hline
\end{tabular}

The study further revealed that majority of the preschool teachers held activities outdoors; indoor space was used scarcely. Qualitative data endorsed that the teachers generally taught mathematics and science in a formal way; operated without a curriculum, or daily schedule or scheme books. Despite having all the materials readily available in the mathematics and science corners, it was noted that only $33 \%$ of the participants used them, occasionally. Blocks, puzzles, songs, rhymes and water play were also used scarcely by them; at times the teachers used flip charts. The teachers however, engaged in activities with improvised objects using bottle tops, figures, stones, sticks, soap, natural/real objects, paints, colours, glue, broom and waste materials.

As compared to SMK, the preschool teachers lacked more in PCK. Their scores in majority of PCK related items ranged from 30\%-57\% (Concept Handling in Preschools-57\%; Childrens' Understanding-55\%; What Children Should Learn-55\%; Developmentally Appropriate Practices42\%; Documentation of children's Mathematics and Science experiences-30\%); interestingly 64\% had knowledge of different Stages of Development of Young Children, these were all trained teachers! (see Table 2 below).

Table 2

\begin{tabular}{ll}
\multicolumn{1}{c}{ PCK of Teachers } \\
\hline Teachers' Knowledgebase & Yes \\
\hline & \\
Familiarity with Stages of Development of Young Children & $64 \%$ \\
Knowledge of Concept Handling & $574 \%$ \\
Awareness of Childrens' Learning & $55 \%$ \\
Knowledge of Childrens' Understanding & $55 \%$ \\
Awareness of Developmentally Appropriate Learning & $42 \%$ \\
Knowledge of Documentation & $30 \%$ \\
\end{tabular}

In the current study, only $42 \%$ of the teachers had knowledge of Developmentally Appropriate Practice (DAP) which is quite alarming. Every preschool teacher needs to be familiar with DAP, the position statement of the National Association for the Education of Young Children 
NAEYC). This introduces them how a teacher/child caregiver nurtures a child's overall development. This guides them to absorb the theories of child development intricately and apply them in classroom situation, understand the individual strengths and needs of each child, and respect the child's cultural and the contextual experiences, the community and the family structure, in order to function effectively as an ECE caregiver. Clearly, in this study, the preschool teachers lacked that and hence were deprived of PCK (Copple \& Bredekamp, 2006). Documentation, a valuable strategy that helps in gaining insights into children's thinking and drive the future curriculum to deepen the children's learning (Seitz, 2008). This was not known to majority of them, only 30\% knew it. They however, possessed knowledge with regards to general pedagogy and didactics and did indicate the dearth of knowledge regarding childrens' varied experiences that relate to the childrens' contextual knowledge.

\section{Best Practice of Mathematics and Science Teaching in Preschools}

To make decisions that reflect best practices, the preschool teachers need to take into consideration the DAP framework, designed to promote young children's optimal learning and development. They need to know about child development and learning; the child as an individual and the child's social and cultural context.

In this study, the teachers' views on the best practice of mathematics and science teaching were captured. The teachers indicated a couple of factors that could ensure befitting outcomes for mathematics and science teaching in preschools (see Table 3 below).

Table 3

Best Practices in Teaching of Mathematics and Science in Preschools Teachers

\begin{tabular}{ll}
\hline Best Practices & Yes \\
\hline & \\
Establishment of Science Centres & $61 \%$ \\
Strong Administrative Support & $100 \%$ \\
& \\
\hline
\end{tabular}

About $2 / 3^{\text {rd }}$ of preschool teachers (61\%) endorsed establishment and use of science Center (SC) as a requirement for teaching of mathematics and science in preschools (Table 3). On probing further, majority of the participants said that children could visit a SC regularly and learn through active participation. They felt that SC can help children relate, remember and differentiate between concepts of mathematics and science, and provide active, handson/practical, developmentally appropriate experience with the help of the SC teacher and the SC attendant. They added by saying that a SC would benefit teachers and enable them to indulge in activities with variety of materials, learn through practice and in turn gain in PCK.

All preschool teachers (100\%) expressed the need for a strong administrative support as crucial for the best results (Table 3). On further probing, they emphasised on the availability of teaching/learning and supportive resource materials, together with required human resources. The teachers further said that school administrators must realise and provide sustained staff-development opportunities through in-service teacher training schedules and workshops. The teachers mentioned that good planning and implementation and continuous evaluation of ECE programme by the administrator is crucial.

\section{DISCUSSIONS}

ECE teachers require a strong knowledge base, both in terms of PCK and SMK to carryout mathematics and science activities in preschools effectively. The current study shows that $80 \%$ of teachers were trained as primary school teachers and almost $3 / 4^{\text {th }}$ of these teachers had 
SMK, which is very important. Literature endorse that ECE teachers must have deep subject knowledge, to challenge and extend children's learning (Hedges \& Cullen, 2005a; Hedges \& Cullen, 2005b; Siraj-Blatchford, Sylva, Muttock, Gilden and Bell, 2002). There's a positive correlation between the amount of mathematics and science-related talk a teacher engages with and the growth of students' knowledge. The preschool teachers' SMK, their background, the years of experience, the level of education and professional qualification determines the quality of engagement in the mathematics and science activities in classrooms. Others, however, consider mathematics and science as difficult subjects to teach, as ECE teachers traditionally are not prepared to teach domain-specific knowledge, aside from literacy, to young children (Brenneman, Stevenson-Boyd \& Frede, 2016). In this study, however, majority were trained Primary School Teachers, and the little mathematics and science teaching in the classrooms could perhaps be attributed to their training in the specific subjects like mathematics and science.

PCK makes preschool teachers aware of childrens' critical conditions for learning and use didactical strategies to make learning feasible. To see the link between the contents (subjects) and the educational activities, and create different opportunities for childrens' learning, and the subject didactics for young children PCK is necessary (Samuelsson \& Carlsson, 2008). A sound knowledge base regarding the developmental milestones of children's mathematics and science thinking and learning, the moments when mathematics and science learning takes place; the assessment procedures of childrens' knowledge regarding a particular concept, and development of plans for future instruction make mathematics and science teaching/learning perfect. The pedagogical knowledge, the didactical strategies like observation, documentation and reflection to highlight concepts, and actively listening to children and responding accordingly are crucial in a preschool context. Similarly, preschool teachers' knowledge to give children opportunities to observe, and to guide the mathematics and science activities make learning better. With PCK, the preschool teachers can interact with children productively and involve sustained shared thinking with the same focus; reflect together with children about the content (Siraj-Blatchford et al., 2002); and make developmentally appropriate, contextual judgments.

The findings show that only 14\% acquired professional training in ECE; and the rest were either trained as primary school teachers or they did not receive any training at all, and yet were working in preschools as teachers and caregivers! Duration of mathematics and science activities and essential types of experiences in EC varies, depending upon the teachers' background, years of experience and levels of education (Piasta, Pelatti \& Miller, 2014). With inadequate PCK, thus, the teachers were unsuccessful in making didactical considerations in the classrooms, explore and explain concepts appropriately in an effective, interesting and understandable manner to the young children. The teachers did not know "how" to give their students "what" about mathematics and science process skills and when to give (Inan, 2010).

Professional development of preschool teachers thus is the need of the hour, otherwise it would limit preschool teachers' imagination and creativity, restrict them to appreciate the significance of varied instructional strategies through which children begin to get the essence of their surroundings, feel the texture of the objects. Literature shows that the teachers who attended 12-20 credit hours of coursework made significant gains on rating scales and prepared their classroom environment more developmentally appropriate, as compared to their counter parts with no ECE coursework (Buell \& Cassidy, 2001). Training with ECE content and pedagogy will capacitate the preschool teachers to infuse developmentally appropriate strategies; understand and implement mathematics and science learning opportunities in their classrooms, whilst integrating them in their daily routines. Such a 
teacher training would help them infuse play, music and story-telling strategies into teaching; engage in experiments, observations, explorations using the learning centres within the classrooms. They would also be able to successfully facilitate a conducive learning environment, scaffold children's mathematics and science thinking; record childrens' prior experience and informal knowledge; document and integrate their experiences into daily routines and transitions. A preschool teacher with a comprehensive ECE training can make a child live and learn mathematics and science concepts (New Jersey Department of Education, 2014). Teachers trained from a robust, comprehensive professional ECE training programme, with content-rich coursework, coupled with practicum and field work (Brenneman et al., 2016) must be used at a foundation level to keep the childrens' curiosity in mathematics and science, along with other subjects, alive.

In the current study, the teachers were selected from private schools, as they were well established. The assumption was that they observed the 2001 Early Childhood Care and Education (ECCE) Policy recommendations along with other policy documents of Botswana, as well as the NAEYC accreditation regulations which emphasise professional ECE training of preschool teachers. But a gap was observed. The good thing is that, the Public/Government preschools that are launched in 2014 onwards to primary schools are governed by the policies of Botswana, and anecdotal evidence endorse the availability of ECE trained teachers in these institutions. Perhaps, the private schools need to abide by the Government policy documents and recruit ECE trained teachers in preschools.

When the issue of Best Practices was raised, a good number of participants (61\%) endorsed SC (science Centre) as an important resource for teaching/learning of mathematics and science concepts to preschool children. EC teachers' knowledge of DAP depends upon academic training in CD/ECE, supervised practical experiences, and content areas covered in CD/ECE courses (Horm-Wingerd, 2001). The role of Science Centre (SC) thus becomes crucial here. A SC can stimulate a process that will influence the pedagogy used in the classrooms and enhance their knowledgebase (Davis \& Simtt, 2003). Creating a cost-effective, fun providing, SC for preschool children, with a stock full of colourful ingredients and equipment, can be amazing for children to learn through their own creations. An effective SC where children use their curiosity to manipulate and investigate objects from the world around them, can make guesses about what is going to happen, and test them too. It includes items that invite exploration, encourage children to use all five senses to learn about the world around them, displays organised materials in rotation regularly to keep them fresh. SC complements other areas of study, provides pictorial step-by-step instructions for simple experiments; allows children to ask open-ended questions to encourage further exploration; considers inviting an older child or adult to be a "visiting scientist" and facilitates in the centre for a day or two each month; models ways to find information, including reading books and searching online; observes the children as they explore, and pay attention to the language and thinking skills they use (Planning a Successful science and Nature Center in Child Care, 2015).

In this study, majority of the participants were trained Primary School Teachers. The dearth of knowledgebase, especially in PCK, could perhaps be bridged by the establishment and use of SC, and hence the endorsement. The Primary School Teachers who were lacking in PCK, could gain profusely from a resource like this! Through SC, the teachers could be encouraged to engage in reflective practice that enables them to generate pedagogical knowledge.

A study examined ECE teachers' knowledge of theories and their relationship to practice and found that teachers made reflections, changed or re-aligned their theories and practice, or both, based on the contexts, and learnt about their own teaching (Wood \& Bennett, 2000). With 
the demonstrations and explanations provided by the SC staff, the teachers who lacked in knowledgebase, could be encouraged to enhance their PCK and SMK. They could be taught to use didactical reflections, scaffold, co-construct, stand-back or guide in some direction, interact and think about how to support learning of different contents keeping in mind the child's interest and the level of understanding. The teachers with basic pedagogical training could enhance the contextual PCK, build their teaching strategy on childrens' everyday life experiences and interests, through SC. They could observe and identify the children's interests and strengths; document them to assess each child; enable them to translate into purposeful planned teaching practices through professional ECE training and SC (New Jersey State Department of Education, 2014).

Strong Administrative Support seemed very important as a strategy by all the participants for having a Best Practice in teaching/learning of science and mathematics in preschools. The key for a successful, effective teaching/learning in preschool is availability of strong administrative support. In a quality ECE programme, both teachers and administrators need to work hand in hand; it is not a task of one professional to assume full responsibility for all the aspects (Marvin, LaCost, Grady \& Mooney, 2003). Administrators need to manage the programmes, provide instructional and program leadership, make effective and efficient budgets for provision of quality curriculum, physical and human resources, and effective overall evaluation. They need to make an agenda to empower preschool teachers through staff development programmes and enhance their knowledgebase, skills and competencies especially (Brenneman et al., 2016; Piasta et al., 2014).

Studies revealed that trained ECE teachers often fail to apply the theories and innovative models of teaching/learning that they leant in classrooms; they fail to connect the knowledge acquired with the classroom practicum experiences; and some of the training often have negligible effect on teachers' firmly held beliefs and conceptions about teaching (Korthagen, Loughran and Russel, 2006; Finson, Thomas \& Pedersen, 2006). It is also found that that teachers who went through specific science teacher training programme that aimed at reformminded instruction never implemented them in the classroom, instead they continued with their earlier classroom practices (Abell, Park Rogers, Hanuscin, Lee \& Gagnon, 2009). The administrator thus could play a crucial role here. The current scenario shows that the teachers recruited in private Gaborone preschools are mostly trained as Primary School teachers. Thus, arranging for short courses/modules and workshops as staff development opportunities, to enhance the SMK and PCK of mathematics and science of preschool teachers would perhaps work ideally to facilitate DAP in classrooms.

The participants of this study also mentioned about provision of support materials necessary as additional as resources. Development of handbooks, teacher guides that explain the pedagogy to be used with preschool children, would not only equip the untrained teachers, but also would capacitate the professionally trained ones, and update their knowledgebase.

\section{CONCLUSION}

ECE teachers' educational experience, professional training profile and knowledgebase determine their classroom practices. It is necessary to build a strong foundation of mathematics and science in young children, in order to hold their interests in these subjects. The preschool teachers need robust knowledgebase, both the SMK as well as PCK that would minimise the constraints and challenges faced in teaching of mathematics and science in classrooms. A situation where, trained teachers, without necessarily being professionally trained in ECE are still being hired, presumably in private preschools of Gaborone, special attention needs to be paid to upgrade their knowledgebase (especially PCK, as it could be 
assumed that any primary school teacher would have acquired SMK of mathematics and science) intermittently, through short courses/modules and workshops.

Science Centre/s should be established in various locations, district-wise, region-wise, and be used regularly where observation, experimentation, exploration is carried out using developmentally appropriate, fun-loving activities. Such an exposure would help preschool children to construct their own knowledge of science and mathematics.

Availability of a strong administrative support and existence of an able leadership is essential for any institution to function effectively. To exercise the Best Practice in teaching of mathematics and science in preschools, the school administrators need to provide state of the art physical resources, support resource materials and choose appropriately qualified human resources; provide various staff development opportunities to Batswana preschool teachers.

The Government of Botswana perhaps could play a very crucial role here. It could not only take a proactive step in the establishment of Science Centre/s for preschool children but could develop a policy that could reinforce the private school administrators to recruit professionally ECE trained teachers, as being done in Public/Government preschools currently. Research needs to be conducted to uncover the conditions that compels a private preschool to recruit teachers who are not professionally trained. Policies need to be built up for retaining trained ECE teachers in private preschools.

Enhancement of knowledgebase of preschools teachers and bringing in the Best Practices of teaching of mathematics and science in preschools would best be done when the professionally qualified and trained teachers work hand in hand with a supportive school administration; and Science Centre/s act as a catalyst to upgrade the knowledgebase of teachers and make children learn the concepts in a developmentally appropriate environment.

\section{ACKNOWLEDGEMENT}

This article is an outcome of the partner driven cooperation project titled as "PCK and SMK in Mathematics and Science in Early Childhood Education" (2012 to 2015) between the University of Gävle (UoG) and University of Botswana (UB). The whole project was funded and supported by the Swedish International Development Agency (SIDA) and Office of Research and Development (ORD), University of Botswana. This part of the study was solely funded by ORD (No.: R955 ECC\&E). Besides the two authors, the $3^{\text {rd }}$ team member Dr. M. Tsamaase participated in data collection and data analysis. Correspondence regarding the article would be done through Prof. Kabita Bose (bose@mopipi.ub.bw).

\section{References}

Abell, S. K., Park Rogers, M. A., Hanuscin, D. L., Lee, M. \& Gagnon, M., J. (2009). Preparing the Next Generation of Science Teacher Educators: A Model for Developing PCK for Teaching Science Teachers. Journal of Science Teacher Education 20(1):77-93.

Bogdan, R. C., \& Biklen, S. K. (2003). Qualitative Research of Education: An Introductive to Theories and Methods (4th ed.). Boston: Allyn and Bacon.

Bose, K. (2012). Scientific Thinking in Preschools of Botswana: is it possible? European Journal of Educational Studies, 4(3), 411-421.

Bose, K. \& Seetso, G. (2016). Science and mathematics teaching through local games in preschools of Botswana. South African Journal of Childhood Education 6(2), a453. http://dx.doi. org/10.4102/sajce.v6i2.453.

Brenneman, K., Stevenson-Boyd, J., \& Frede, E. C. (2009). Mathematics and science in preschool: policies and practice. preschool policy brief. ERIC, Institute of Education Sciences. 19. Retrieved from https://eric.ed.gov/?id=ED534142. 
Bose, K., \& Seetso, G. (2019). Teachers' SMK And PCK OF Mathematics And Science Affect Teaching In Gaborone Preschools. Advances in Social Sciences Research Journal, 6(12) 114-127.

Buell, M. J., \& Cassidy, D. J. (2001). The complex and dynamic nature of quality in early care and educational programs: A case for chaos. Journal of Research in Childhood Education, 15(2), 209-219.

Castro, F. G., Kellison, J. G., Boyd, S. J., \& Kopak, A. (2010). A methodology for conducting integrative mixed methods research and data analyses. Journal of Mix Methods Research, 4(4), 342-360. doi:doi:10.1177/1558689810382916.

Clements, D. (2001). Mathematics in the Preschool. Teaching Children Mathematics, 7, 270.

Copple, C. \& Bredekamp, S. (2006). Basics of Developmentally Appropriate Practice: An Introduction for Teachers of Children 3 to 6. Washington, DC: National Association for the Education of Young Children (NAEYC).

Creswell, J. W. (2013). Research Design: Qualitative, Quantitative, and Mixed Methods Approaches (2nd ed.). Thousand Oaks, CA: Sage.

Darling-Hammond, L. (2000). How teacher education matters. Journal of Teacher Education , 51, 166-173.

Early Childhood Program Administration. (2017). Resources, Training, Best Practices, Sharing. Retrieved from http://ecadmin.wikidot.com/.

Essa, E. L. (2013). Introduction to Early Childhood Education. Belmont, USA: Wardsworth.

Fernandez, C. (2014). Knowledge Base For Teaching And Pedagogical Content Knowledge (PCK): Some Useful Models And Implications For Teachers' Training. Problems of education in the 21st century, 60, 79-100.

Finson, K., D., Thomas, J. A., \& Pedersen, J. E. (2006). Comparing Science Teaching Styles to Students' Perception of Scientists. School science and mathematics, 106(1):8-15.

Gallenstein, N. L. (2004). Creative discovery through classification (early childhood corner). Teaching children mathematics, 11, 103-108.

Garbett, D. (2003). Science Education in Early Childhood Teacher Education: Putting Forward a Case to Enhance Student Teachers' Confidence and Competence. Research in Science Education, 33(4), 467- 481.

Gay, L., Mills, G., \& Airasian, P. (2009). Educational research competencies for analysis and applications. Columbus: Pearson.

Grossman, P. (1990). The making of a teacher: Teacher knowledge and teacher education. Columbia University, New York: Teachers College Press.

Hedges, H., \& Cullen, J. (2005a). Meaningful teaching and learning: Children's and teachers' content knowledge. ACE Papers, 16, 11-24.

Hedges, H., \& Cullen, J. (2005b). Subject knowledge in early childhood curriculum and pedagogy: Beliefs and practices. Contemporary Issues in Early Childhood, 6(1), 66-79.

Horm-Wingerd, Diane. (2001). New Teachers for a New Century: The Future of Early Childhood Professional Preparation. USA: DIANE Publishing.

Inan, H. Z. (2010). Examining Pre-School Education Teacher Candidates' Content Knowledge and Pedagogical Content Knowledge. Kuram ve Uygulamada Eğitim Bilimleri/Educational Sciences . Theory \& Practice, 10 (4), 2309-2323.

Kallery, M., \& Psillos, D. (2001). Preschool Teachers' Content Knowledge in Science: understandings of elementary science concepts and of issues raised by children's questions. International Journal of Early Years Education, 9(3), 165-177.

Korthagen, Fred A.J., Loughran, J. J. \& Russell, T.. (2006). Developing fundamental principles for teacher education programs and practices. Teaching and Teacher Education, 22 (8), 1020-1041.

LIU, S. (2010). Teachers' knowledge: Review from comparative perspective. New Horizons in Education, 58(1), 148-158.

Marvin, C., LaCost, B., Grady, M. \& Mooney, P. (2003). Administrative Support and Challenges in Nebraska Public School Early Childhood Programs: Preliminary Study. Topics in Early Childhood Special Education. https://doi.org/10.1177/02711214030230040301.

Mathangwane, T. J. (2011). Trends in International Mathematics and Science Study (TIMSS). Gaborone: Botswana Examinations Council.

Moomaw, S. (2011). Teaching Mathematics in Early Childhood. Baltimore, USA: Brookes Publishing Company. 
New Jersey Department of Education. (2014). Preschool Teaching and Learning Standards. https://www.nj.gov/education/ece/guide/standards.pdf.

Oers, B. V. (2010). Emergent mathematical thinking in the context of play. Educational Studies in Mathematics, 74(1), 23-37.

Piasta, S. B., Pelatti, C. Y., \& Miller, H. L. (2014). Mathematics and Science Learning Opportunities in Preschool Classrooms. Early Educational Development, 25(4), 445-468.

Planning a Successful Science and Nature Center. (2019). Childcare. USA: eXtension.

Republic of Botswana. (1994). Revised National Policy of Education. Gaborone: Government Printers.

Republic of Botswana. (2015). Education \& training sector strategic plan (ETSSP 2015-2020). Gaborone: Government Printers.

Republic of Botswana. (2017). Education in Botswana. Gaborone: Government Printers. Retrieved from https://en.wikipedia.org/wiki/Education_in_Botswana.

Shulman, L. S. (1986). Those who understand: knowledge growth in teaching. Educational Researcher, 15 (4), 4-14.

Samuelsson, P., I., \& Johansson, E. (2006). Play and learning - inseparable dimensions in preschool practice. Early Child Development and Care, 176(1), 47-65.

Samuelsson, I., P. \& Carlsson, Maj A. (2008). The Playing Learning Child: Towards a pedagogy of early childhood. Scandinavian Journal of Educational Research, 52 (6), 623-641.

Siraj-Blatchford, I., Sylva, K., Muttock, S., Gilden, R., \& Bell, D. (2002). Researching Effective Pedagogy in the Early Years. Research report No 356. DfES. London: HMSO.

Tashakkori, A., \& Teddlie, C. (2009). Foundations of Mixed Methods Research Integrating Quantitative and Qualitative Approaches in the Social and Behavioral Sciences. USA: Sage Publications. Inc.

Wiersma, E. W., \& Jurs, S. G. (2009). Research Methods in Education: An Introduction, 9th Edition. USA: Pearson. 